\title{
La Teoría Crítica como perspectiva de análisis de las relaciones de dominación y los procesos de descentralización en Chile
}

\author{
A Critical Theory as an analysis perspective on domination relations and decentralization \\ processes in Chile
}

\section{A Teoria Crítica como perspectiva de análise das relações de dominação e dos processos de descentralização no Chile}

\author{
Pablo Aurélio Monje-Reyes ${ }^{1}$ \\ Universidad Alberto Hurtado / Departamento de Ciencia Política y Relaciones Internacionales y carrera de Administración Pública, Chile
}

\begin{abstract}
Resumen
Este artículo tiene como objetivo discutir los elementos centrales de la Teoría Crítica para el análisis de las relaciones de poder en el Chile actual. La discusión se centra en la relación entre dominantes y dominados, en la estructura de administración territorial del Estado de Chile. Metodológicamente se desarrolla un análisis de principales premisas elaboradas por los autores de la Teoría Crítica, para contrastarlas con elementos prácticos del proceso de descentralización político-administrativa del Estado chileno. Se reflexiona sobre las reformas estructurales del Estado implementadas en la década de los 1980 y si éstas han traído consigo cambios en las relaciones de poder. El eje central de debate con la teoría son las políticas de modernización del Estado, enfocadas en la descentralización del poder político-administrativo, las cuales se han desarrollado en los últimos 30 años por intermedio de las nuevas formas de gobierno regional y local. Estas nuevas instancias de gobierno han permitido la participación, en forma directa o indirecta, de la ciudadanía en las acciones de gobierno y gestión pública. Sin embargo, este artículo concluye, tanto desde la perspectiva teórica como de la praxis, que las lógicas y formas de dominación del Estado chileno se siguen manteniendo inalterables; aún más, se han perfeccionado a través de la creación de organismos descentralizados del poder. Se mantienen los conflictos territoriales, la relación centro-región es de dominación de arriba hacia abajo. Por lo tanto, esto deja en entredicho que las políticas de modernización del Estado, sustentadas en procesos de descentralización, permiten modificar las relaciones de poder entre dominantes y dominados.
\end{abstract}

Palabras clave: Teoría Crítica. Dominación. Estado. Descentralización. Burguesía.

\begin{abstract}
This article aims at discussing the key elements of Critical Theory for the analysis of power relations in today's Chile. The discussion focuses on the relation between dominant and dominated ones, in the territorial administration structure of the State of Chile. Methodologically, an analysis of main assumptions prepared by the authors of Critical Theory is conducted, in order to contrast them with practical elements of the process of political and administrative decentralization of the Chilean State. We think through the structural State reforms implemented in the 1980s and whether they have brought along changes in power relations. The core of debate with the theory are the State modernization policies,
\end{abstract}

Artículo enviado en 19 de febrero de 2014 y aprobado para publicación en 3 de diciembre de 2014.

\section{DOI: http://dx.doi.org/10.1590/1679-395116756}

1 Doctorando en Ciencias Sociales y Magister en Gestión y Políticas Públicas de la Universidad de Chile; Administrador Público de la Universidad de Los Lagos; actualmente se desempeña como profesor e investigador del Departamento de Ciencia Política y Relaciones Internacionales y carrera de Administración Pública de la Universidad Alberto Hurtado - Chile. Email : pamore7@gmail.com 
focusing on the decentralization of political and administrative power, which have been developed over the past 30 years through new forms of regional and local government. These new government instances have allowed, directly or indirectly, the participation of citizenship in actions taken by government and public management. However, this article concludes, both from the theoretical and practical perspectives, that the domination rationales and forms of the Chilean State have been kept unchanged; moreover, they have been improved through the creation of decentralized power agencies. Territorial conflicts remain, the center-region relation constitutes a top-bottom domination. Therefore, this puts into question that State modernization policies, grounded in decentralization process, allow changing power relations between dominant and dominated ones.

Keywords: Critical Theory. Domination. State. Decentralization. Bourgeoisie.

\section{Resumo}

Este artigo tem por objetivo discutir os elementos centrais da Teoria Crítica para a análise das relações de poder no Chile atual. A discussão centra-se na relação entre dominantes e dominados, na estrutura de administração territorial do Estado do Chile. Metodologicamente, desenvolve-se uma análise das principais premissas elaboradas pelos autores da Teoria Crítica, para contrastá-las com elementos práticos do processo de descentralização político-administrativa do Estado chileno. Reflete-se acerca das reformas estruturais do Estado implementadas na década de 1980 e se elas trouxeram mudanças das relações de poder. O eixo central de debate com a teoria são as políticas de modernização do Estado, focadas na descentralização do poder político-administrativo, que foram desenvolvidas nos últimos 30 anos, por meio das novas formas de governo regional e local. Essas novas instâncias de governo permitiram, direta ou indiretamente, a participação da cidadania nas ações do governo e da gestão pública. No entanto, este artigo conclui, tanto sob a perspectiva teórica como a da práxis, que as lógicas e as formas de dominação do Estado chileno têm-se mantido inalteradas; além disso, elas aperfeiçoaram-se por meio da criação de órgãos descentralizados do poder. Os conflitos territoriais continuam, a relação centro-região é de dominação de cima para baixo. Portanto, isso põe em xeque o fato de que as políticas de modernização do Estado, baseadas em processos de descentralização, permitem modificar as relações de poder entre dominantes e dominados.

Palavras-chave: Teoria Crítica. Dominação. Estado. Descentralização. Burguesia.

\section{Elementos Introductorios}

En los debates sobre procesos histórico-institucionales del Estado Chileno, entre ellos las relaciones de dominación y los procesos de descentralización, tradicionalmente surgen dos miradas. Por una parte, una perspectiva positivista de carácter empírico - analítico, que en Chile se ha asociado fuertemente a la visión de la economía neoclásica, tanto en las reglas de su método de investigación, como en la interpretación de sus resultados. Por otra parte, la perspectiva comprensiva-interpretativa, que observa y analiza el proceder de las instituciones y de las formas legales de dominación, desvinculadas de los sujetos sociales.

Considerando que ambas miradas analíticas son eminentes descriptivas, y por tanto conservadoras, parece pertinente analizar la descentralización del poder en Chile y las formas de dominación del Estado, mediante un instrumental teórico - analítico de orientación crítico-reflexiva, como es la Teoría Crítica (HORKHEIMER, 1937; HABERMAS, 1989; ADORNO, 2001; BEART y CARREIRA DA SILVA, 2010; LARRAÍN, 2010; RITZER, 2002; VILLALOBOS, 2010). En efecto, la Teoría Crítica no descansa exclusivamente en la descripción de los hechos sociales, sino más bien en una aproximación crítica de la realidad social misma y su transformación.

En términos prácticos, las ideas de la Teoría Crítica se sustentan en que la realidad social es transformable y su estudio permite entregar herramientas para cambiarla. En palabras de Horkheimer:

"El juicio categórico es propio de la sociedad preburguesa: es así, el hombre no puede cambiar nada. La forma hipotética y disyuntiva de los juicios responde especialmente al mundo burgués: en determinadas circunstancias puede aparecerse este efecto, es así o bien 
de otra manera. La teoría crítica afirma: no debe ser así, los hombres pueden cambiar el ser" (HORKHEIMER, 1937).

Desde la mirada anterior, la Teoría Crítica busca volver a Marx, con la idea central de unificar la teoría con la práctica, y potenciar la relación entre ellas. Por tanto, la Teoría Crítica pretende revelar las condiciones estructurales de las acciones humanas, y su fin último es superar las condiciones de dominación.

Una de las principales preocupaciones de la Teoría Crítica son las relaciones asimétricas o de poder en las sociedades. Esto pone de relieve que la crítica reflexiva es la forma de acción con la cual se analizan las condiciones sociales presentes, que son inducidas por procesos de dominación. Mediante esta crítica reflexiva, el sujeto obtendría las herramientas para liberarse de las condiciones de dominación, legitimadas por la maquinaria ideológica para generar su sometimiento arbitrario y subjetivo. De esta forma, como señala Habermas (1987) la tarea analítica se orienta hacia una hermenéutica de los supuestos que sustentan las relaciones de dominación:

"El conocimiento o la interpretación se basan necesariamente en presupuestos implícitos que están enraizados en la historia y en la tradición, pero de esto no se desprende que los diferentes conjuntos de presupuestos sean igualmente válidos. La sociología es una "hermenéutica de la profundidad" que proporcione un patrón con el que evaluar tradiciones diferentes de forma crítica e identificar distorsiones ideológicas, así como su vínculo con las relaciones de poder" (HABERMAS, 1987a).

En síntesis, la Teoría Crítica descansa en la explicación causal de la dominación, siendo la autoemancipación su fin último.

A continuación se aplica la Teoría Crítica al análisis de las formas de dominación y descentralización territorial del Estado en Chile. Para ello, se realiza una breve descripción del contexto histórico político del Estado chileno, para posteriormente analizar las relaciones de dominación y los procesos de descentralización.

\section{El contexto histórico - político.}

Durante los últimos 40 años, el Estado de Chile ha pasado por grandes transformaciones de carácter socio político. En la década de los ochenta se institucionalizó una nueva forma de Estado, por medio de la Constitución de la República elaborada en plena dictadura militar. En ella se dan las nuevas formas de dominación racional legal, que la Burguesía le impone a las clases subalternas que componen la sociedad chilena. Coloca en el centro de esta nueva institucionalidad el rol de las fuerzas armadas, como garantes de la misma. Define, a través de la doctrina de seguridad nacional, el uso del territorio y dinamiza su administración por medio de la creación de nuevas formas burocráticas de administración territorial. Concentra los esfuerzos del Estado en el desarrollo y puesta en marcha de los ajustes necesarios del modo producción capitalista, dejando atrás los procesos de industrialización y dando paso al proceso de mercantilización de la economía, con un fuerte carácter primario exportador. Esto trajo consigo un cambio profundo en el uso del territorio nacional, en cuanto a la actividad productiva regional. Un ejemplo es el caso de la regiones del Bío Bío y Araucanía, zonas de alta producción de granos en la décadas de los setenta y ochenta, hoy son zonas de producción forestal, con alta capacidad de exportación o de inserción en el mercado mundial. 
Cuadro 1

\section{Canasta Exportadora de la VIII Región del Bío-Bío}

En porcentajes

\begin{tabular}{l|r|r|r|r|r|r}
\hline Ramas de Actividad & \multicolumn{1}{|c|}{1990} & \multicolumn{1}{|c|}{1996} & \multicolumn{1}{c}{1997} & \multicolumn{1}{c|}{1998} & 1999 & \multicolumn{1}{c}{2000} \\
\hline Agricultura & 2,2 & 0 & 0 & 0 & 0 & 0 \\
\hline Industria de Alimentos & 22 & 26,3 & 0 & 24,6 & 19,6 & 13,8 \\
\hline Forestales & 28,8 & 24,8 & 0 & 27,14 & 33,3 & 29,1 \\
\hline Textiles & 0 & 1,4 & 1 & 0 & 0 & 0 \\
\hline Fab. Celulosa, Papeles y Cartones & 29,7 & 35,6 & 32,4 & 36,6 & 36 & 44 \\
\hline Refinería Petroleo & 2,5 & 0 & 2 & 1,5 & 0 & 2,2 \\
\hline Industria Básica de Hierro y Acero & 4,1 & 1,5 & 1,3 & 1,6 & 1,6 & 1,5 \\
\hline Productos de Barro y Loza & 1,1 & 0 & 0 & 0 & 0 & 0 \\
\hline Productos Metalicos & 0 & 0 & 0 & 1,2 & 1 & 0 \\
\hline Productos Quimicos Básicos & 0 & 0 & 0 & 0 & 0 & 1,7 \\
\hline Extracción de madera bruto & 7,1 & 4,4 & 4,7 & 1,1 & 2,1 & 1,5 \\
\hline Total & 97,5 & 95,2 & 94,2 & 94 & 93,6 & 93,8 \\
\hline
\end{tabular}

Fuente: Elaborados en Base a la Dirección de Aduanas, 2001

División de Planificación del MIDEPLAN, 2002

El cuadro 1 nos muestra como las exportaciones de maderas y celulosa en la década de los noventa hasta inicios del presente lustro fueron incrementado. La industria básica del hierro y acero cae en un 50\% de su aporte de las exportaciones de la región. Es decir la manufactura desaparece y la producción de alimentos cae en un $100 \%$. Solo crece la industria forestal y deriva de la misma.

\section{Cuadro 2}

\section{Canasta Exportadora de la IX Región del Araucanía}

En porcentajes

\begin{tabular}{l|r|r|r|r|r|r}
\hline Ramas de Actividad & \multicolumn{1}{|c|}{1990} & \multicolumn{1}{c|}{1996} & \multicolumn{1}{c|}{1997} & \multicolumn{1}{c|}{1998} & 1999 & \multicolumn{1}{c}{2000} \\
\hline Agricultura & 16,3 & 2,7 & 13,7 & 14,7 & 15 & 11,7 \\
\hline Frutas & 0 & 0 & 2,4 & 3,1 & 1,6 & 1,7 \\
\hline Ganadería & 0 & 0 & 1,8 & 0 & 0 & 0 \\
\hline Industria Alimento & 7,5 & 28,5 & 28,3 & 19,7 & 5,3 & 9,1 \\
\hline Cobre y Hierro & 0 & 0 & 0 & 0 & 0 & 3,3 \\
\hline Extracción de Madera & 0 & 0 & 0 & 0 & 1,3 & 1,9 \\
\hline Bebidas y Liquidos & 25,2 & 2,7 & 1,3 & 0 & 0 & 1,4 \\
\hline Forestales & 34,4 & 40,3 & 27 & 39,2 & 37,5 & 33,4 \\
\hline Muebles & 14,9 & 21,3 & 24,5 & 21,3 & 37,9 & 35,7 \\
\hline Papely Cartón & 0 & 1,1 & 0 & 0 & 0 & 0 \\
\hline Total & 98,3 & 96,6 & 99 & 98,9 & 98,6 & 98,2 \\
\hline
\end{tabular}

Fuente: Elaborados en Base a la Dirección de Aduanas, 2001

División de Planificación del MIDEPLAN, 2002

El cuadro 2 indica como las exportaciones de maderas y celulosa en la década de los noventa hasta inicios del presente lustro fueron incrementado en conjunto con el sector muebles. La agricultura cae en un 50\% su 
aporte de las exportaciones de la región, de la misma manera pero cae con más velocidad la industria alimentaria y de bebidas y líquidos. Solo crece la industria forestal y deriva de la misma.

De aquí se desprende consigo los cambios en las vocaciones productivas regionales, sustentados en las ideas de ventajas competitivas y comparativas de los territorios, para la producción de determinados bienes y servicios, que fueron fundamentalmente primarios.

Desde el punto de vista socio político, la Constitución de 1980 instala la idea de un poder centralizador, que dirige los conflictos territoriales y de clases de las burguesías regionales y las clases subalternas. Se desarrollan instrumentos administrativos que le permita a la burguesía nacional administrar el conflicto de clase en las regiones, como también el conflicto principal centro - región. Estos instrumentos son la creación de formas de gobierno y administraciones en las nuevas regiones creadas por la Constitución, cuyas autoridades dependen del poder ejecutivo del Estado central.

Desde la perspectiva de la Teoría Crítica, el escenario instalado por la Constitución de 1980 instaló nuevas formas de dominación del Estado, con una expresión territorial llamada región, como parte de un diseño institucional -aparentemente - descentralizado.

\section{Sociedad, territorio y descentralización.}

Es importante tener una aproximación conceptual de sociedad que permita guiar el análisis y sostener las dimensiones críticas que emergen del debate teórico. En estos términos, como señala Adorno:

"La teoría de la sociedad debería trascender las evidencias inmediatas en busca del conocimiento de su fundamento en la sociedad y preguntarse por qué los hombres siguen desempeñando un rol. Éste fue el propósito de la concepción marxiana del carácter como máscara, que no sólo anticipa la categoría, sino que la deduce socialmente" (ADORNO, 2001 ed.)

Desde esta perspectiva, el concepto de sociedad no puede ser mirado solo como un cúmulo de hechos sociales, contingentes al rol que cada hombre y mujer desarrolla en los distintos niveles de la estructura social. Esto nos permite una aproximación crítica a los diseños institucionales en Chile. Sobre todo en los cambios que modifican las relaciones socio políticas del modelo de dominación. En el caso de análisis propuesto, son las nuevas relaciones sociales de dominación que articulan sociedad - territorio y administración. Sin embargo, para observar se requiere profundizar la concepción de sociedad con algunos elementos que permiten darle mayor densidad en el análisis del caso.

"La misma humanidad determinada como clientela, el sujeto de las necesidades, está, más allá de toda representación ingenua, preformada socialmente, y no sólo por el nivel técnico alcanzado por las fuerzas productivas, sino también por las relaciones económicas, por más difícil que sea verificar esto empíricamente. Previamente a cualquier estratificación social concreta, la abstracción del valor de cambio va del dominio de lo universal sobre lo particular, del dominio de la sociedad sobre quiénes son sus miembros forzosos. Dicha abstracción no es socialmente neutra, a diferencia de lo que aparenta el carácter lógico de la reducción de las unidades tales como el tiempo de trabajo social medio". (ADORNO, 2001 ed.)

Esta afirmación entrega elementos complementarios. Permite entender críticamente que un análisis de roles no es suficiente para tener una mirada crítica de la sociedad. Por el contrario, advierte que lo central y lo importante es la relación de dominio determinado de lo universal a lo particular, que en el caso puesto en 
cuestión es la relación de dominio del Estado Central con las regiones, situando la dimensión del Estado Central como poder ejecutivo y como garante del orden social, lo cual es una función de carácter principal del Estado en la dimensión de "dominación de los hombres sobre los hombres" (ADORNO, 2001).

Siendo el aspecto central la dominación, el Estado tiene y puede adquirir diversas dimensiones, que le permiten funcionalizar las formas de dominio. Esto se logra por medio de nuevas formas de administración, que enmascaran las relaciones de dominación, que principalmente son desde la cúspide social hacia la base social, es decir, de arriba hacia abajo. Un ejemplo es la figura del Intendente, que tiene el rol de representante del Presidente de la Republica en la Región y es designado por éste, pero a la vez es Jefe de Gobierno de la Región y dirige el poder ejecutivo regional. Por tanto, mediante esta forma de gobierno y administración se captura el gobierno de la región por parte del poder central. En términos teórico- críticos:

“... las administraciones de todos los países de la tierra tienden compulsivamente a autonomizarse respecto de los administrados y a reducirlos a meros objetos de procedimientos regulados abstractamente,.... su racionalidad se funda en la especialización de los procesos técnicos y los adoptados a éstos, pero también su lado ideológico".

(ADORNO, 2001 ed.)

Es importante el aporte de Adorno para develar que las técnicas de administración son una parte del componente ideológico de la dominación. De hecho, no cabe duda de esto ya que, en gran medida, el proceso de reorganización estatal a nivel territorial del Estado Chileno, siempre fue argumentado desde las técnicas económico - políticas y administrativas, mostrando y/o ejemplificando las virtudes de una regionalización y descentralización del país, como un factor clave en la modernización del Estado. Sin embargo, ha sido y es un factor clave para la implementación del proyecto de liberalización de mercados, paso necesario para la institucionalización de la economía social de mercado en las regiones del país.

Los componentes de dominación de una sociedad producen formas de adaptación social, que de una manera u otra, logran su objetivo de sometimiento. En el caso en análisis lo podemos definir como el sometimiento de las regiones al centro político - administrativo del Estado, como territorios de dominación racionalizada. De hecho, el ejemplo más notable se expresa en las movilizaciones sociales de la región de Aysén (región austral ubicada en la Patagonia Chilena), que desafiaron al poder central y sus mecanismos represivos de dominación. El movimiento finalizó con una parte de los dirigentes sociales perseguidos por la Ley de Seguridad Interior del Estado, mientras que otra parte de los dirigentes negociaba en la Casa de la Moneda espacio simbólico del poder ejecutivo centralizador del Estado Republicano de Chile. Al negociar en La Moneda, los dirigentes regionales no pudieron vencer el proceso de adaptación a las relaciones y procesos sociales - en el caso analizado el centralismo dominante- que desde la perspectiva de la Teoría Crítica, se sedimenta en hombres y mujeres, siendo difícil librarse de ellas, por ser un mecanismo principal de dominación:

"La adaptación de los hombres a las relaciones y procesos sociales que constituyen la historia y sin que la que los hombres difícilmente hubieran podido sobrevivir, se ha sedimentado en ellos de tal modo que cada vez les es más difícil librarse de ella, aunque sólo sea en la conciencia, sin enredarse en conflictos pulsionales insoportables" (ADORNO, 2001 ed.)

Las relaciones y procesos sociales dominantes en la relación Estado central - regiones, se establecen la idea de que quien resuelve los conflictos y la gestión territorial, tanto para los dominados como los dominadores, es el poder ejecutivo central. Esto es independiente de que en las regiones existan representantes de la burguesía, que dependen de las acciones de la burguesía centralista que tiene el poder del Estado y el poder del capital. Un ejemplo, es el caso de la burguesía que explota la salmonicultura del sur austral del país. En la última década esta burguesía produjo su propia crisis, al desarrollar su actividad productiva en forma intensiva, sin resguardos medioambientales, generando una caída en su producción, por el virus isa, que 
contagió en forma extensiva el cultivo de salmones. Esto se tradujo en una caída de su producción, consecuentemente, de sus ingresos monetarios, y por tanto, en no poder dar respuesta a sus compromisos financieros con la banca nacional (la burguesía financiera), a la cual no le interesa el desarrollo regional, ni menos las fuentes productivas, sino la renta del capital de riesgo. A partir de estos intereses, la banca exigió sus rentas de capital, llevando a la quiebra a una parte muy importante de la industria del salmón en las regiones de Los Lagos y Aysén. Un elemento significativo es que las negociaciones no se desarrollaron en las sedes regionales de la banca. Por el contrario, todas fueron en la sede central que, al igual que el poder político del Estado, tiene su punto de convergencia territorial en la ciudad de Santiago.

Otros ejemplos de conflictos Estado central - regiones, que se pueden mencionar, son el término de la explotación del carbón en la cuenca del Golfo de Arauco, en la década de los noventa, y la crisis de la pesca extractiva, de carácter permanente y que abarca casi todas las regiones del país. También, el conflicto actual develado por los municipios de perfil territorial minero, que demandan fondos complementarios para su gestión, como compensación por la extracción de la principal riqueza minera del país en sus territorios, como es el cobre.

Otro conflicto de gran envergadura es el histórico de los pueblos originarios, en particular el pueblo Mapuche en el sur del país, que es agravado por los intereses de la burguesía que explota el sector forestal en territorios de reclamación originaria. De la misma manera, los conflictos entre las comunidades agrícolas y las grandes mineras, por la propiedad del agua en el norte chico.

Por último, lo que no significa que existan otras crisis ocultas al ojo crítico, los conflictos medioambientales por los proyectos de centrales de generación de electricidad, representados por los principales dueños del capital del país y sus socios transnacionales, con grupos medio ambientalistas y comunidades locales.

Los conflictos mencionados son parte del modelo dominación y tienen una expresión socio territorial. Desde la perspectiva de Adorno, estas crisis cíclicas de permanencia temporal, se traducen como:

"La cimentación social que anteriormente procuraban las ideologías se ha trasladado, por una parte, a las poderosísimas relaciones sociales existentes como tales, y por otra, a la constitución sicológica de los hombres" (ADORNO, 2001 ed.).

De hecho, las relaciones institucionales que la burguesía - a través del aparato estatal - ha definido con su territorio, reproducen el tipo de relaciones sociales que se producen en las regiones. Los conflictos y las crisis entre las regiones y el poder central se resuelven desde el poder central, y no desde las regiones. Esto ha ido configurando una percepción en los sujetos individuales sobre la relación con el poder central y su capacidad de dominio, que en términos socio - culturales se expresa en la siguiente afirmación que representa un lugar común: "ir a Santiago es ir a Chile". Esto significa que la relación simbólica con la ciudad capital, es claramente de sometimiento, por parte de los sujetos regionales, al dominio de la burguesía nacional, propietaria del poder central, tanto desde el punto de vista político como económico, administrativo y "cultural” del país.

\section{Síntesis}

La Teoría Crítica, para el análisis de las formas de dominio y descentralización en Chile, es un constructo epistemológico adecuado. ¿Por qué esta afirmación? Primero, porque los elementos que constituyen la episteme de la Teoría Critica son claves para el análisis, a saber, a) la búsqueda permanente de las formas de dominación, b) la preocupación permanente por la asimetría de poder, c) la crítica a la regularización o naturalización de las relaciones sociales de parte de la burguesía, d) la crítica al positivismo metodológico y al control técnico de la sociedad, e) la crítica a las historias oficiales y descriptivas de los dominadores y las relaciones de dominación. Segundo, y más importante que los anteriores, por una razón fundamental: la 
Teoría Crítica coloca en el centro de la acción investigativa e interpretativa, la capacidad del hombre y las mujeres de cambiar su realidad. Por tanto, la Teoría Crítica nos entrega un bagaje teórico y conceptual de gran proyección para entender la realidad. En particular, no se queda en la interpretación sino que busca el cambio de la realidad. La Teoría Crítica está inmersa en la relación bidireccional de la teoría - práctica. Tanto la teoría se nutre de práctica, como la práctica se nutre de la teoría.

A lo largo de este ensayo se pudo constatar la capacidad de la Teoría Crítica de explicar y situar, epistemológicamente, los elementos presentes en el eje de análisis del ensayo, vale decir, dominación y descentralización en Chile. Surgen cuatro elementos importantes: a) la sociedad chilena hoy contiene nuevas relaciones sociales de dominación, que se articulan entre sociedad - territorio y administración; b) el sometimiento del centro político - administrativo del Estado a las regiones, como territorios de dominación racionalizada; c) nuevas formas de administración que enmascaran las relaciones de dominación, que principalmente son desde la cúspide social hacia la base social, es decir, de arriba hacia abajo; y d) la idea de que quien resuelve los temas de conflicto y gestión territorial, tanto para los dominados como los dominadores, es el poder ejecutivo central. Esto es independiente de que en regiones existan representantes de la burguesía, que dependan de la burguesía centralista, que no solo tiene el poder del Estado sino también el poder del capital.

\section{Referencias}

ADORNO, T. Epistemología y Ciencias Sociales. Frónesis, Cátedra, Universitat de Valencia. Traducción Vicente Gómez. Madrid: Ediciones Cátedra, 2001.

BEART, P.; CARREIRA DA SILVA, F. La Teoría Social Contemporánea. Traducción María Hernández. Madrid: Alianza Editorial, 2010

DIVISIÓN DE PLANIFICACIÓN REGIONAL - Ministerio de Planificación y Cooperación. Las Exportaciones Regionales de Chile en la Perspectiva de la Globalización - Período 1990-2000. Santiago de Chile, 2002.

HABERMAS, J. Conocimiento e Interés. Madrid: Editorial Taurus, 1989a.

HORKHEIMER, M. Teoría Tradicional y Teoría Crítica. Barcelona: Ediciones Paidós; I.C.E. de la Universidad Autónoma de Barcelona, 1937.

LARRAÍn, J. El Concepto Ideología. Postestructuralismo, Postmodernismo y Postmarxismo. Primera Edición. Santiago de Chile: LOM Ediciones, 2010. v. 4.

RITZER, G. (Ed.) Teoría Sociológica Moderna. Quinta Edición. Traducción María Teresa Casado. Madrid: Editorial Mc Graw Hill, 2002.

VILlalobos, M. Ciencia Social como Crítica Social. La revolución epistemológica de Karl Marx. Santiago de Chile: LOM Ediciones, 2010. 